\title{
A Comparative Study of Low-Voltage Ride-Through (LVRT) Control of Grid-Interfaced Doubly-Fed Induction Generator (DFIG)
}

\author{
Muhammad Naveed ${ }^{1}$, Prof. Dr. Muhammad Naeem Arbab ${ }^{2}$ \\ ${ }^{1,2}$ University of Engineering and Technology, Peshawar Pakistan \\ naveedepe@gmail.com ${ }^{1}$, mnarbab@yahoo.com ${ }^{2}$ \\ Received: 15 December, Revised: 28 December, Accepted: 31 December
}

\begin{abstract}
Due to the fast increase in energy of modern human being the desire for the clean renewable energy is increasing day by day. Electrical power generation from wind is promising source. But due to the large combination of wind forms in electrical power grid the stability and security are key issues for the electrical power engineers. Amongst the required grid codes for the power utilities LVRT is very important. According to LVRT the wind form should act as conventional power plant and connect to grid for some particular time to provide stability to grid at normal and fault time. In this paper we have developed a LVRT strategy for control of active, reactive power and DC link voltage of the variable speed wind turbine. The test bed system is 9 MW DFIG wind turbine attached to $120 \mathrm{KV}$ grid system by $30 \mathrm{KM}$ long $25 \mathrm{KV}$ transmission line. The modelling and simulation is done by using MATLAB/SIMULINK. The control system is implemented by using PI controller using vector or field oriented control. The LVRT strategies implemented on test bed model are (STFCL), DC chopper, Rotor Crowbar and Hybrid strategy with using RSC control, GSC control and pitch control mechanisms. The hybrid strategy provides excellent solution for LVRT of DFIG wind turbine by controlling power (active and reactive) and voltage of DC link. The results of hybrid strategy during symmetrical fault is best and well suited to the LVRT requirements as compared of STFCL, DC chopper and crowbar.
\end{abstract}

Keywords-DFIG, LVRT, STFCL, DC chopper.

\section{IINTRODUCTION}

The usage of energy is growing due to the population increase and industrialization of the modern world. The use of traditional fossil fuel is increasing every day. This has created the energy shortage, environmental pollution, and the alarming situation of global warming. Due to these factors, todays the renewable energy is very much attractive and demanding type of energy. Amongst the renewable sources the wind power is widely and easily available. Therefore, there is rapid growth of using wind power technologies globally. The installations of wind power in 2018 was higher than $52 \mathrm{GW}$. The expectation for wind power in 2019 is higher [1]. Due to the greater number of wind power plants present in power system grid and dynamic behavior of wind turbines there is serious issue of grid stability, security and control. So many countries have developed the new grid codes for the steady operation of grid system. The new codes of grids demand that the wind turbine well have to work like hydro and thermal plants during normal operations and at a time of fault to provide sustenance to grid system. In the latest grid codes, the main issue is (LVRT) or (FRT) ability when fault occurs on grid and is very essential for engineers in electrical power system [2], [3]. According to LVRT the wind turbine should be attached to grid during faults for a particular time after that it should be allowed to disconnect. Furthermore, the wind turbine will have to work as like the conventional power plants to provide back up to the grid [2], [3].

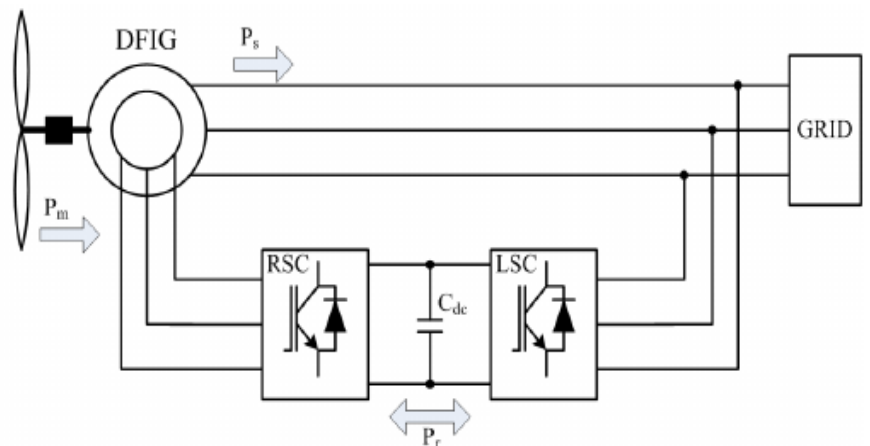

Fig. 1. DFIG based wind turbine configuration with partial scale convertors.

Among various wind turbines (WT), DFIG-WT as in Figure. 1 is very well known due to its favorable features, such as (a) Greater efficiency, (b) greater speed variation, (c) active and reactive power is controlled without the effect of each other, (d) low Rating of Grid side converts (GSC)and Rotor side convertor (RSC), (e) reduced mechanical force and (f) better quality of power [4].However the dynamic behavior of the DFIG based WT is serious problem at the time of voltage dip because its stator is directly attached to grid [5], and due to the reduced scale convertors that are attached to the rotor of 
DFIG. Therefore, when fault accrues at a far location from the DFIG WT the voltage at grid connection point GCP is reduced due to which the voltage of rotor, DC link and current increased [6]- [9]. So if we did not use any protection and control scheme these high voltage and currents would harm the power electronics convertor and the Wind turbine speed is increased to a danger level. This is also a great risk for the turbine operation Until we designed it suitably [6][12].Therefore the focus of this paper is to properly investigate the capability of LVRT of DFIG at the time of faults on grid and to give suitable control for LVRT solution that can provide safety and security to the DFIG WT during faulty grid condition. The proposed control strategy is Hybrid including Stator Type Fault Current Limiter (STFCL), DC Chopper, Rotor Side convertor (RSC) and Grid Side Convertor using PI controller.

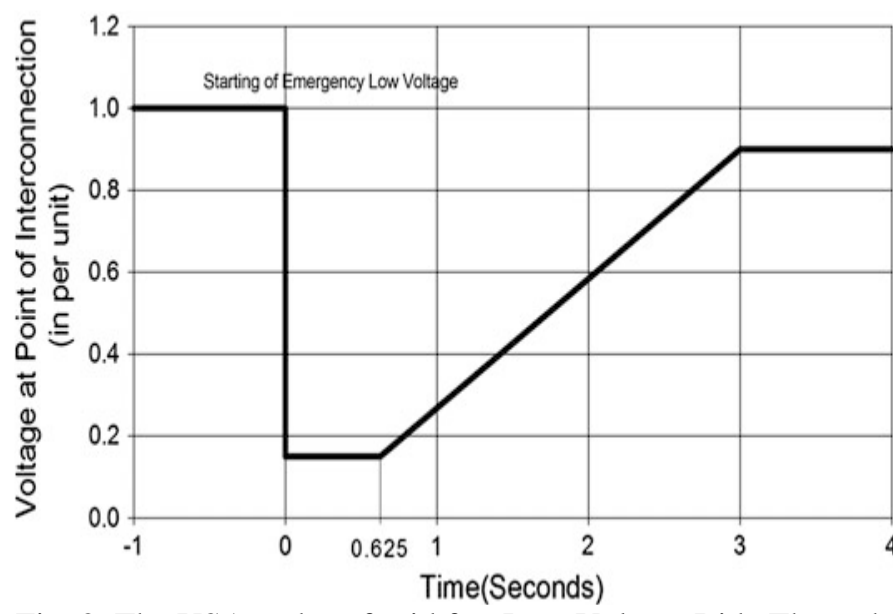

Fig. 2. The USA codes of grid for Low Voltage Ride Through [13].

\section{DFIG MODELLING}

For the wind power industry, the improvement of LVRT of DFIG is very important challenge. The mathematical model of DFIG make us capable of analyzing the behavior during generic conditions.so here we want to know about the DFIG dynamic model. For the derivation of DFGIG model we use the equation the magnetic flux linkages. The equation of motion and voltages which are associated with stator and rotor of DFIG machine is also very important.

\section{A. Equation of Voltage for DFIG}

The Figure 3 shows the model which is equivalent of DFIG. This model is for synchronous speed.

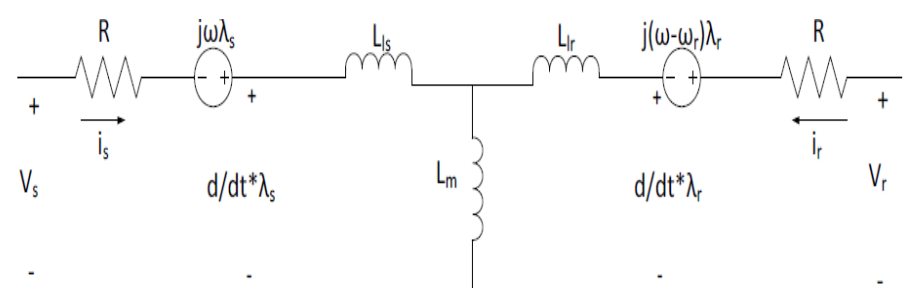

Fig. 3. DFIG space vector equivalent circuit model
From the above figure it is clear that the stator and rotor voltages are denoted as

$$
\begin{gathered}
V_{s}=R_{s} i_{s}+d \lambda_{s} /_{d t}+j \omega \lambda_{s} \\
V_{r}=R_{r} i_{r}+d \lambda_{r} /_{d t}+j\left(\omega-\omega_{r}\right) \lambda_{r}
\end{gathered}
$$

In the above equation $\mathrm{Vs}, \mathrm{Vr}$ are voltages.

The $\mathrm{Rs}, \mathrm{Rr}$ represents the resistances. The Is, Ir are the currents a. The $\lambda s, \lambda r$ is for the Flux linkages $(W b){ }^{\omega}$ is the rotating speed of arbitrary reference frame $(\mathrm{rad} / \mathrm{s}) .{ }^{\omega_{F}}$ is used for angular speed in $(\mathrm{rad} / \mathrm{s})$.

In the above equations the subscript that have been used are $\mathrm{s}$ for stator and $\mathrm{r}$ for rotor. The terms $\mathrm{j}{ }^{\omega \lambda_{\mathrm{S}}}$ and $\mathrm{J}\left(\omega_{s-} \omega_{r}\right)^{\lambda_{r}}$ are used to represents the voltage induced..

\section{B. Equation of Flux linkages}

The equation of the flux linkages can be represented as

Where

$$
\begin{gathered}
\lambda_{s}=\left(L_{l s}+L_{m}\right) i_{s}+L_{m} i_{r}=L_{s} i_{s}+L_{m} i_{r} \\
\lambda_{r}=\left(L_{l r}+L_{m}\right) i_{r}+L_{m} i_{s}=L_{m} i_{s}+L_{r} i_{r}
\end{gathered}
$$

$$
\begin{aligned}
& L_{s}=L_{l s}+L_{m} \\
& L_{r}=L_{l r}+L_{m}
\end{aligned}
$$

In the above equations $\lambda s, \lambda r$ are used for the flux linkages of stator and rotor side. Ls is used to represent the stator selfinduced flux in hennery $(\mathrm{H})$. Lr is for Rotor self-induced flux in hennery $(\mathrm{H}) . \mathrm{Lm}$ is representing the inductance in $(\mathrm{H})$ of magnetizing. The Lls, Llr are the leakage Inductances $(\mathrm{H})$.

\section{Motion equation}

The Mechanical motion can be represented in terms of electromagnetic and mechanical torque using the following equation

$$
\begin{aligned}
& J \frac{d \omega_{m}}{d t}=T_{e}-T_{m} \\
& \mathrm{~T}_{\mathrm{e}}=\frac{3 \mathrm{P}}{2} \mathrm{R}_{\mathrm{e}}\left(\mathrm{j} \lambda_{\mathrm{s}} \mathrm{i}_{\mathrm{s}}\right) \\
& \mathrm{T}_{\mathrm{e}}=-\frac{3 \mathrm{P}}{2} \mathrm{R}_{\mathrm{e}}\left(\mathrm{j} \lambda_{r} \mathrm{i}_{r}\right)
\end{aligned}
$$

In the above equations of (3) $\mathrm{J}$ is used for moment of inertia of rotor in the unit $\left(\mathrm{Kgm}^{2}\right)$. Te represents the electromagnetic torque. $\omega_{r}$ is used to represent rotor speed, and $\omega_{m}=\frac{\omega_{r}}{p} . \mathrm{P}$ is used to denote the poles pairs of DFIG. Tm denotes the Mechanical torque of generator shaft in the unit of Newton meter $(\mathrm{Nm})$

If we combine all the above equation, we can obtain the space vector model for the DFIG. The space vector model is changed to synchronous reference frame. The synchronous speed is given by 
$\omega_{s}=2 \pi f$

$\omega_{S 1}=\omega_{g}-\omega_{r}$

Where $\omega_{\triangle 1}$ is speed of slip and the $\omega_{\sigma}$ is the synchronous speed at the electrical frequency $f_{s}$ of stator. As the stationary reference is static therefore the value of $\omega$ is set to zero.

\section{D. $d q$ Reference frame Model}

For the DFIG model we can use stationary or dq reference frames. In stationary reference frame the model parameters like inductance capacitances and resistances changes with time. For analyzing the performance of the DFIG we will have to use dq reference frame in which the equivalent circuit parameters such as inductance, resistances and voltages etc does not changes with time and remain constant with time. Using the dq reference frame the axes of $\mathrm{d}$ and $\mathrm{q}$ are separated at 90 degrees and therefore we can use the decoupled control.

The equations for different circuit parameters such as voltage, flux linkages and motion is derived if we divide Equations in to real and imaginary parts. Thus the new equation obtained in the form of

$V_{s}=V_{d s}+j V_{q s} ; i_{s}=i_{d s}+j i_{q s} ; \lambda_{s}=\lambda_{d s}+j \lambda_{q s}$

$V_{r}=V_{d r}+j V_{q r} ; i_{r}=i_{d r}+j i_{q r} ; \lambda_{r}=\lambda_{d r}+j \lambda_{q r}$

E. Voltage equation using dq reference frame

By splitting the real and imaginary parts the dq components of voltage will be

$$
\begin{aligned}
& V_{s d}=R_{s} I_{s d}+d \lambda_{s d} / d t-\omega \lambda_{s q} \\
& V_{s q}=R_{s} i_{s q}+d \lambda_{s q} / d t+\omega \lambda_{s d} \\
& V_{r d}=R_{r} i_{r d}+d \lambda_{r d} /_{d t}-\left(\omega-\omega_{r}\right) \lambda_{r q} \\
& V_{r q}=R_{r} i_{r q}+d \lambda_{r q} /_{d t}+\left(\omega-\omega_{r}\right) \lambda_{r d}
\end{aligned}
$$

\section{F. Equation for flux linkage in dq axis}

The flux linkage equation for the dq components is given by

$$
\begin{aligned}
& \lambda_{s d}=L_{s} i_{s d}+L_{m} i_{r d} \\
& \lambda_{s q}=L_{s} i_{s q}+L_{m} i_{r q} \\
& \lambda_{r d}=L_{m} i_{s d}+L_{r} i_{r d} \\
& \lambda_{r q}=L_{m} i_{s q}+L_{r} i_{r q}
\end{aligned}
$$

\section{G. Equation of motion in the dq axis}

The torque (electromagnetic) is achieved in different ways. The mostly used expression in literature are below

$$
T_{e}=\left\{\begin{array}{l}
\frac{3 P}{2}\left(I_{q s} \lambda_{d s}-I_{d s} \lambda_{q s}\right) \\
\frac{3 P L_{m}}{2}\left(I_{q s} L_{d r}-I_{d s} I_{q r}\right) \\
\frac{3 P L_{m}}{2 L_{r}}\left(I_{q s} \lambda_{d r}-I_{d s} \lambda_{q r}\right)
\end{array}\right.
$$

The equivalent dq model of the DFIG is given below.

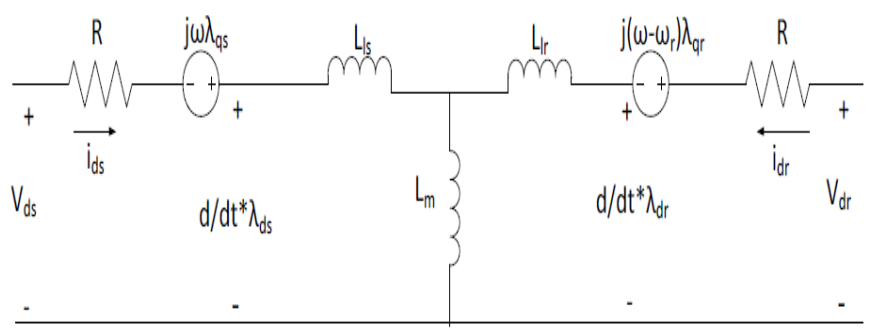

(a) d-axis model

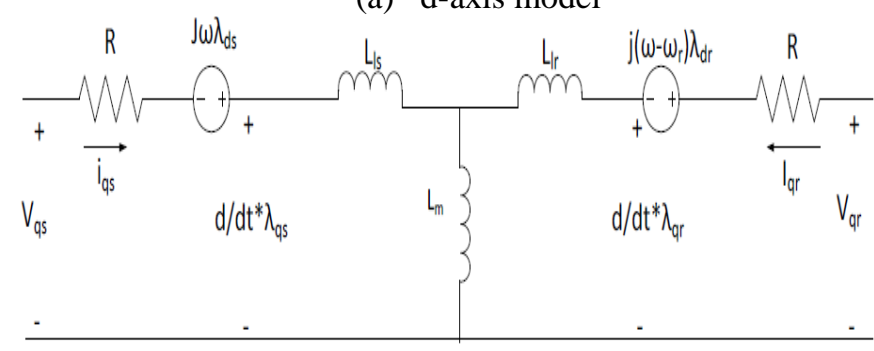

(b) q-axis model

Fig. 4. dq axis model for DFIG

\section{H. Relation for speed, active power and torque}

If we neglect the resistive losses, then the power of stator and rotor is

$$
P_{r} \cong s P_{s}
$$

And the mechanical power is also expressed as

$P_{m} \cong P_{s}-s P_{s} \cong P_{s}(1-s)$

As we know that

$$
(1-s)=\omega_{m} / \omega_{s}
$$

$$
P_{m} \cong \frac{\omega_{m}}{\omega_{s}} P_{s} \cong T_{e m} \omega_{m} / P
$$

From the above Equation the relation between Ps and electromagneti4.tqunque is given by

$$
P_{s} \cong T_{e m} \omega_{s} / P
$$

Similarly, the rotor power can be expressed as 


$$
P_{r} \cong T_{e m} \omega_{r} / P
$$

From the above equations it is clear that the DFIG can be operated in many ways. That is the DFIG can be operated in different modes. These are very important relation

\section{PROPOSED LVRT STRATEGIES}

As mentioned earlier that (DFIG) attached to grid must have to work as stated by the condition of (LVRT) when fault occurs. The LVRT condition required that the DFIG be attached to the grid system at faulty condition and provide assistance by providing active and reactive power to grid. Therefore, different LVRT strategies are discussed in literature. Amongst various hard ware strategies, the DC Chopper and (STFCL) are very effective.so our proposed LVRT strategy is the hybrid of these two strategies.

\section{A. DC Chopper Circuit}

This circuit is actually a combination of resistor, switch and freewheeling diode. These elements are attached in parallel of the capacitor of DC- link to supress the high voltage peaks of convertor DC bus as in shown in figure.5. At the time fault occurs on grid the high power flows to convertors and voltage level at DC bus increased [14]. In [15] the authors have also used the chopper control for over voltage protection.

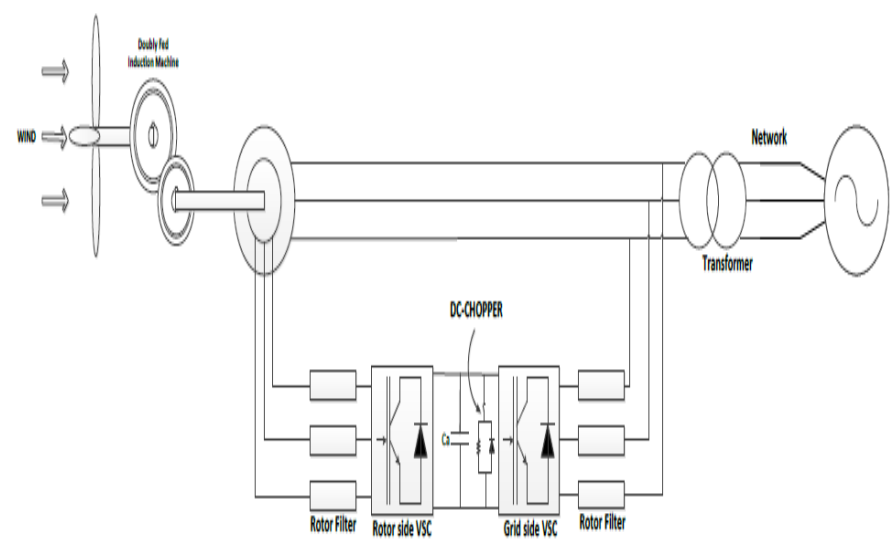

Fig. 5. DFIG Chopper circuitry [16]

At normal operation the switch is open when fault take place then the switch become closed and resistor is placed in circuit, this resistor dissipate the high extra energy and voltage peaks is filtered. The purpose of using Freewheeling diode is that it blocks the stress when the switch is off [17].

\section{B. Stator type fault current limiter switch (STFCL)}

STFCL as shown below worked for the improvement of the LVRT of DFIG. The purpose of using the STFCL is that it provides protection to the DFIG power electronics circuitry.it also provide safety to the grid system during fault when the torque is increased. From the figure below it is clear that it has a transformer for isolation purposes.it has a switch $\left(S_{d}\right)$ which is a semiconductor type. This switch is normally closed switch. When the fault occurs at grid this switch detects the fault and the switch is opend.by opening this switch the fault current limiting circuitry is introduced to the fault. The STFCL circuit has also a bridge circuit consists of diodes. In parallel of the bridge it has a capacitor called snubber capacitor $(\mathrm{Cf})$ and a resistor $(\mathrm{Ra})$ and capacitor $(\mathrm{Ca})$ which are in series to each other and parallel to snubber capacitor for the purposes of limiting the fault current as shown in Fig. 5.2.

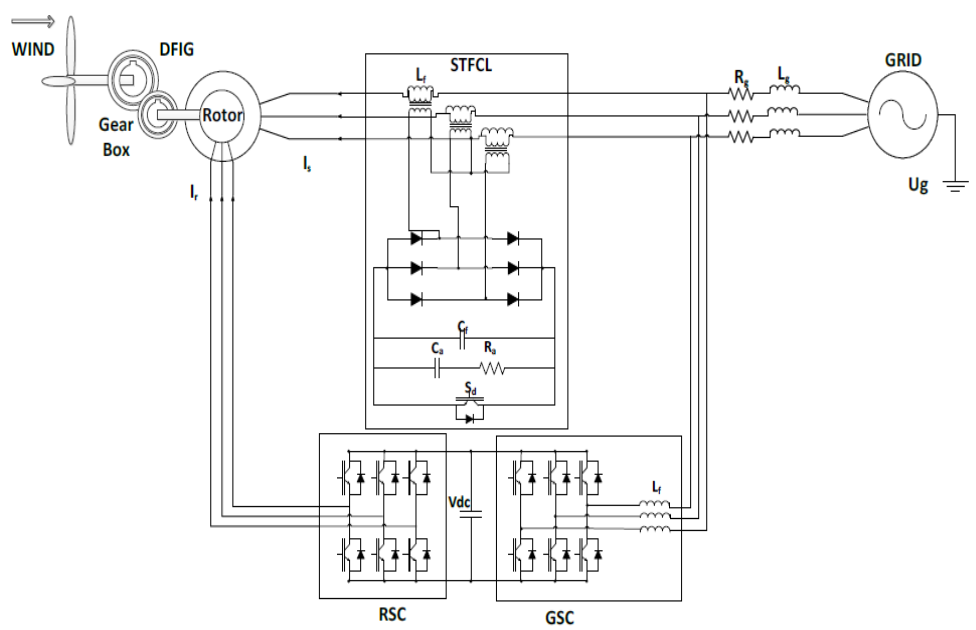

Fig. 6. DFIG Stator type fault current limiter switch [18]

At the time when there is not any fault, the switch is normally closed and the inductor $\mathrm{L}$ is not inserted in in the circuit. But when the fault occurs the switch is opened. At initial stage the current at fault is controlled by the L1, the ( Ra) and the $(\mathrm{Ca})$. At last time when the capacitor reaches to it full capacity the current flowing to bridge is stopped. At that time the inductor is fully placed in the stator for controlling current and the EMF is also weakens [19], [20],[21]

\section{Hybrid strategy}

This hybrid strategy is the combination of both the above strategies (DC Chopper + STFCL). This is our proposed strategy that is implemented in this paper as shown in the below figure.

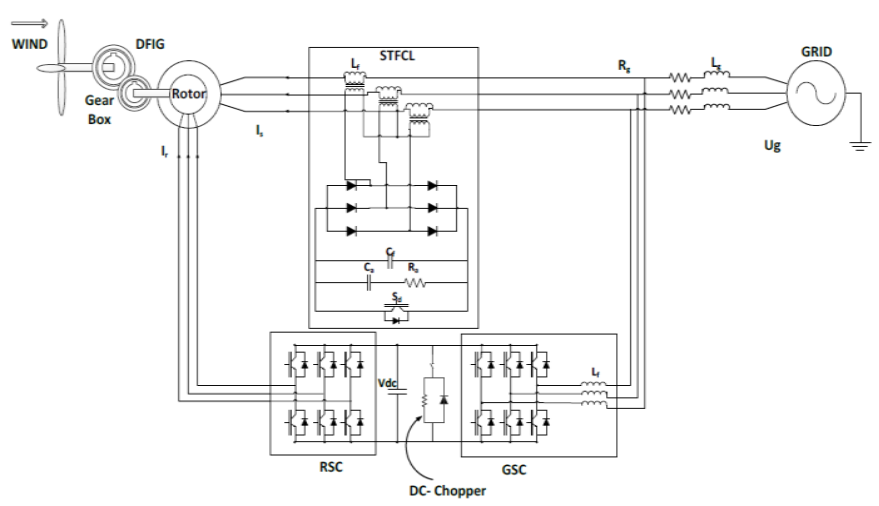

Fig. 7. DFIG Hybrid strategy

\section{CONTROL SYSTEM FOR DFIG}

The control system makes us capable to regulate the flow of current of rotor. If we regulate current flow to rotor, then its output power is controlled and it is also possible to get maximum efficiency. We will use the Vector control system. It is very better control method and is widely used. In this method the real power is independently control without the effect of 
reactive control and vice versa. The generator and convertor in DFIG based WECS acts like a current regulated voltage source invertor.

In DFIG based WECS there are two power convertors (a) the rotor side convertor (RSC) and (b) the Grid side convertor (GSC). These convertors are attached by a capacitor called DC link capacitor. This DC link capacitor works for the storing the excessive energy and filters the voltage peaks. The purpose of RSC is to control the speed, torque and power. The GSC maintains the value of the voltage of DC link constant. It keeps control of reactive power as well [12].

\section{A. Rotor side convertor (RSC) control system block diagram}

The control system block diagram for RSC is shown in figure 8 . The stator voltage oriented control (SVOC) is used for the RSC control. The Qs calculator calculate the stator position angle $\theta_{s}$ and $\theta_{r}$ is find out by the using of an encoder. The rotor slip angle $\theta_{s \rrbracket}$ is

$$
\theta_{s i}=\theta_{s}-\theta_{r}
$$

Different variable can be transform by (abc to dq ) block and similarly from the dq reference frame can be transform to abc by (dq to abc) block[22],[23]. The stator angle $\theta_{s}$ is find out by

$$
\theta_{s}=\tan ^{-1} \frac{V_{\beta}}{V \alpha}
$$

And the stator dq voltage will be given by

$$
\left[\begin{array}{l}
V_{\alpha} \\
V_{\beta}
\end{array}\right]=\frac{2}{3}\left[\begin{array}{rrr}
1 & -\frac{1}{2} & -\frac{1}{2} \\
0 & \frac{\sqrt{3}}{2} & -\frac{\sqrt{3}}{2}
\end{array}\right] \cdot\left[\begin{array}{l}
V_{a s} \\
V_{b s} \\
V_{c s}
\end{array}\right]
$$

The Vas, Vbs and Vcs a re the three phase stator voltages.

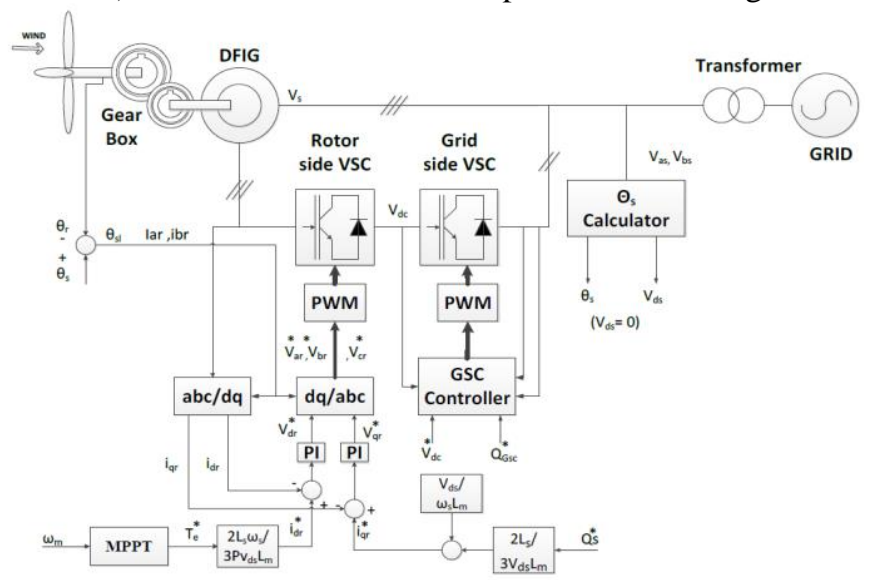

Fig. 8. (RSC) control system block diagram

The MPPT method (that is an optimum method) for torque production is utilized to find out reference torque (electromagnetic) Te. The ${ }^{i} d y$ is generated by the second block by tacking the reference torque $T_{e}$ as input. The dq axis reference voltage $V_{d y}$ and $V_{Q r}$ is transformed from the dq axis

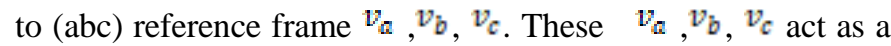
modulator signal for the PWM invertor. After that modulating signal is matched with carrier signal and the error signal worked as gating signal for the invertor device. Thus (RSC) control perform the two main functions. Controlling of power of the DFIG independently.

\section{B. Grid side convertor (GSC) control for DFIG}

This control system which is voltage oriented is one of the common scheme used for (GSC) control is shown in Fig. 9 below. In this control scheme the changing from the $(\mathrm{abc})$ to (dq) reference is used [24], [25].

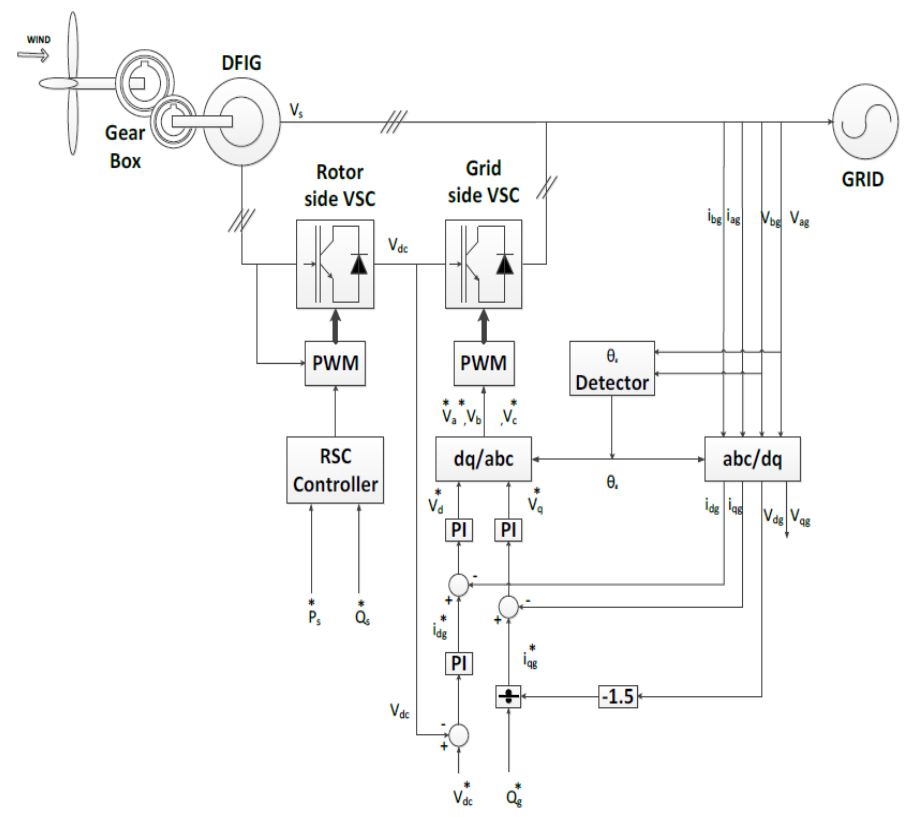

Fig. 9. (GSC) control system for DFIG

$\theta_{g}$ is needed for transferring ( $\mathrm{abc}$ ) to dq reference. For voltage angle $\theta_{g}$ calculation various methods are used but here we have used Phase locked loop (PLL) method. For the transformation from stationary $(\mathrm{abc})$ reference to dq reference we need to measure the balance values for the three phase voltages $v_{a}, v_{b}, v_{c}[29]$.

We can find $\theta_{g}$ with following formula.

$$
\theta_{g}=\tan ^{-1} \frac{V_{\beta}}{V_{\alpha}}
$$

Where $V_{\alpha}$ and $V_{\beta} \quad$ can be find by the following transformation

$$
\left[\begin{array}{l}
V_{\alpha} \\
V_{\beta}
\end{array}\right]=\frac{2}{3}\left[\begin{array}{rrr}
1 & -\frac{1}{2} & -\frac{1}{2} \\
0 & \frac{\sqrt{3}}{2} & -\frac{\sqrt{3}}{2}
\end{array}\right] \cdot\left[\begin{array}{l}
V_{a g} \\
V_{b g} \\
V_{c g}
\end{array}\right]
$$

For the balance three phase voltages system we will have $V_{a g}+V_{b g}+V_{c g}=0$. So we have 
$\left(\begin{array}{l}V_{\alpha} \\ V_{\beta}\end{array}\right)=\frac{2}{3}\left(\begin{array}{c}V_{a g}-\frac{1}{2} V_{b g}-\frac{1}{2} V_{c g} \\ \frac{\sqrt{3}}{2} V_{b g}-\frac{\sqrt{3}}{2} V_{c g}\end{array}\right)=\left(\begin{array}{c}V_{a g} \\ \frac{\sqrt{3}}{3}\left(V_{a g}+2 V_{b g}\right)\end{array}\right)$

From the above equation (19) it is clear that for VOC only two voltages $V_{a g}$ and $V_{b g}$ are enough. Practically the voltage signals from the grid are in distorted form having harmonics. So we use PLL practically to calculate the angle $\theta_{g}$.

In VOC $i_{a g} i_{b g}$ and $i_{\operatorname{cg}}$ are calculated and transformed to dq components currents $i_{d g}$ and $i_{q g}$. Then By using $i_{d g}$ we control Ps and by using $i_{q g}$ we control the Qs.

As we know that the in VOC $V_{g d}$ is equal to zero.

$V_{q g}=\sqrt{V_{g}^{2}-V_{d g}^{2}}=0$

And the power is

$$
\left\{\begin{array}{c}
\mathrm{P}_{s}=\frac{3}{2}\left(V_{d g} I_{d g}+V_{q g} I_{q g}\right)=\frac{3}{2} V_{d g} I_{d g} \\
\mathrm{Q}_{s}=\frac{3}{2}\left(V_{q g} I_{d g}-V_{d g} I_{q g}\right)=-\frac{3}{2} V_{d g} i_{q g}
\end{array}\right.
$$

Equation (21) clearly indicates that the Ps is controlled with $i_{d g}$ and the Qs with $i_{q g}$. And the reference current of the qaxis is

$$
i_{q g}^{*}=-\frac{Q_{g}^{*}}{1.5 V_{d g}}
$$

$Q_{g}^{*}$ in the above equation represents the reference value of the grid reactive power. Its value is positive, negative or unity.

The PI controller produce the signal of $i_{d g}$ according to the operating condition. That $i_{\mathbb{d g}}$ is used for the controlling of the active power Ps.

If we consider the ideal switch, then the DC active side power is equal to the invertor $\mathrm{AC}$ side power and mathematically it is represented as

$$
P_{g}=\frac{3}{2} V_{d g} I_{d g}=V_{d c} I_{d c}
$$

V. Simulation Results and Performance Evaluation

The results and behavior of the different LVRT strategies is tested using MATLAB SIMULINK software. The testing model is 9MW DFIG WT attached with grid. Which transmit electrical power to $120 \mathrm{KV}$ power grid by $25 \mathrm{KV}$ long transmission line. The wind is flowing with $11 \mathrm{~m} / \mathrm{s}$. The fault (short circuit) is enforced at $30 \mathrm{KM}$ transmission line. The duration of fault is $300 \mathrm{~ms}$.
Four LVRT strategies (1) Hybrid (2) (STFCL) (3) DC Chopper and (4) Crowbar are critically compared with (RSC) control, (GSC) control and pitch control is also implemented. The results are tested for symmetrical (three line to ground) (LLL-G) occurred on the transmission line and the voltage of DC Link is controlled using PI Controller.

\section{A. Symmetrical faults}

The figures (10) -(18) clearly gives the results of different LVRT strategies for the voltage of power Grid and current, voltage of DC link, active and reactive power, electromagnetic torque rotor current and voltage and the electromagnetic torque for the Symmetrical (three line to ground) fault of the grid interfaced DFIG. The fault occurs from 1 to 1.3 seconds (300ms) on $30 \mathrm{Km}$ long transmission line.

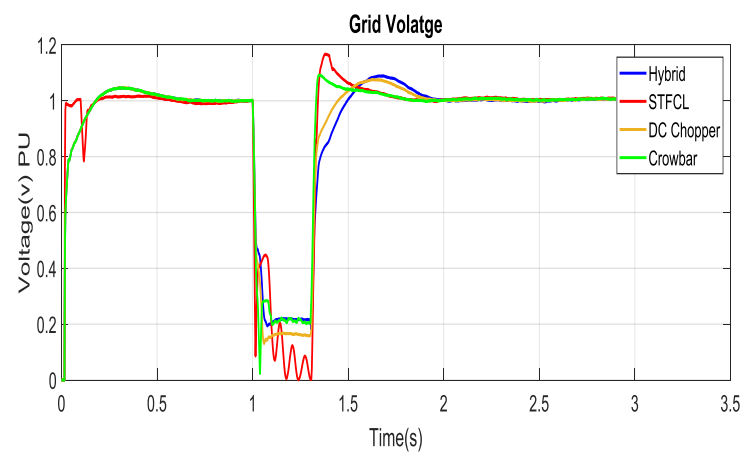

Fig 10. Grid Voltage

Figure 10 gives the grid voltage response of different strategies for the grid interfaced DFIG during symmetrical (LLL_G) fault. Sever voltage dip is for the STFCL.it is the lowest and has high oscillations. The hybrid strategy has lowest voltage dip of all and is smoother. The response of the DC chopper and Crowbar is in between hybrid and STFCL.

Grid Current

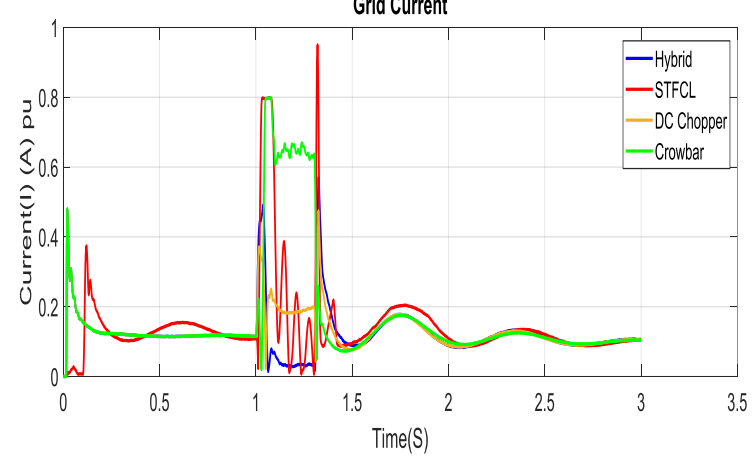

Fig 11: Grid current

The figures 11 shows the grid current response of different strategies for the grid interfaced DFIG during symmetrical (three line to ground) (LLL-G) fault. STFCL strategy has very high oscillations and peaks. The 2 nd highest response is of the Crowbar and 3rd highest is of DC chopper strategy. The hybrid strategy has lowest current oscillations and peaks.so the hybrid is better of all the strategies. 


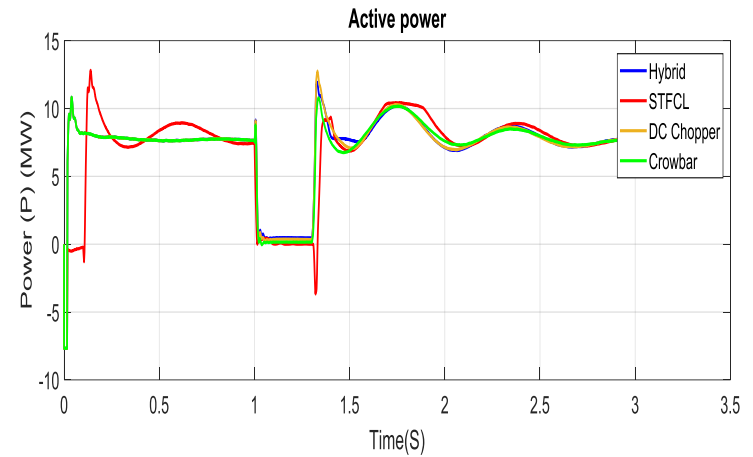

Fig 12: Active power

Figure 12 gives the Active power performance of different strategies for the grid interfaced DFIG during symmetrical (LLL-G) fault. It clearly shows the Hybrid strategy provide excellent results, the reaction of the STFCL is that it has below $0 \mathrm{MW}$ power during grid fault. The crowbar and DC Chopper have approximately same active power response that is between the hybrid and STFCL.

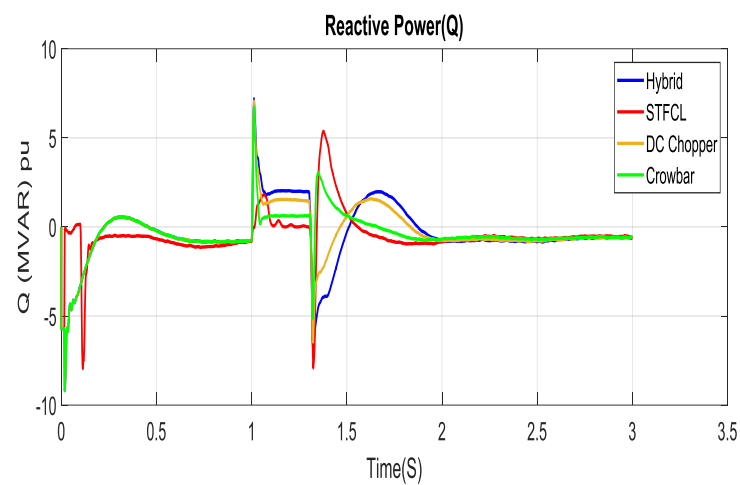

Fig 13: Reactive Power

Figure 13 shows the reactive power response of different strategies of grid interfaced DFIG during symmetrical (LLL-G) fault. The response of the Hybrid is again very good. It provides better MVAR as compared to the other strategies. The response of the STFCL is poor, it injects $0 \mathrm{MVAR}$ to the grid during fault and after fault it has very great spikes. The DC chopper and Crowbar have better results than STFCL but poor than hybrid.

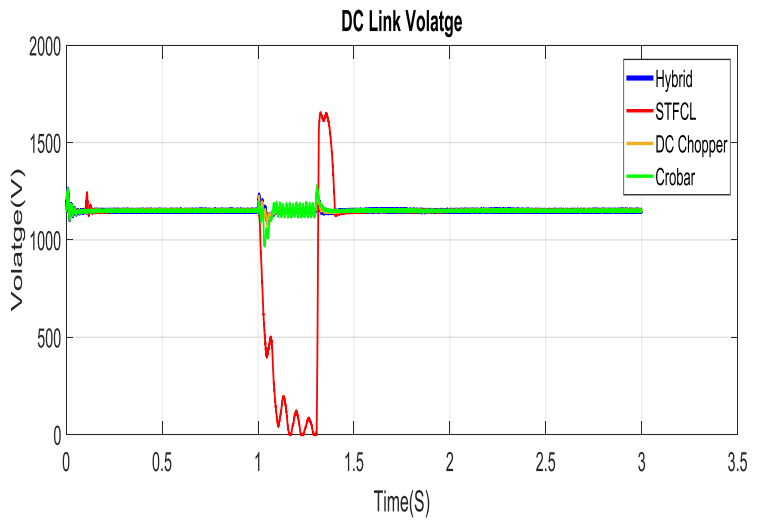

Fig 14: DC Link voltage
The figure 14 clearly indicates the voltage for the DC link response of different strategies of the grid interfaced DFIG during symmetrical (LLL-G) fault. The Hybrid strategy reduce the DC link voltage very effectively and have low oscillations. The STFCL voltage during grid faults falls to $0 \mathrm{~V}$ and has spikes of above $1500 \mathrm{~V}$. The voltage spikes of the crowbar and DC chopper have voltage spikes nearer to $1250 \mathrm{~V}$. The Hybrid have good response have lowest voltage spikes.

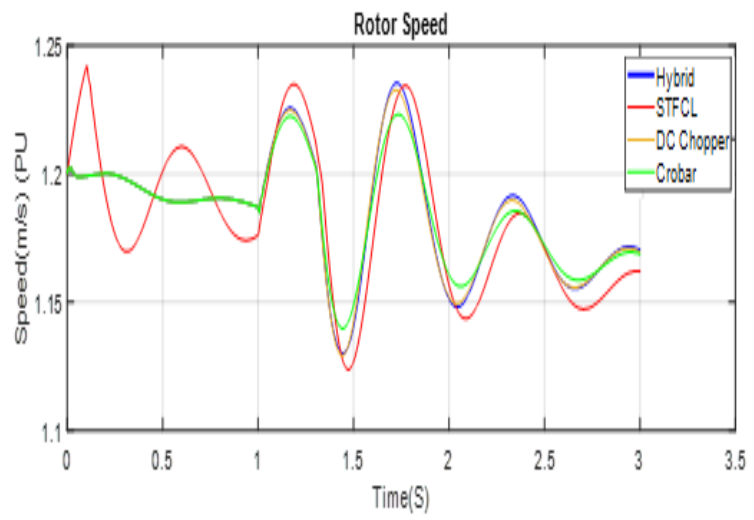

Fig 15: Rotor speed

Figure 15 clearly indicates the rotor speed reaction of different strategies for the grid interfaced DFIG during symmetrical (LLL-G) fault. The figure clearly indicates that hybrid has rotor speed nearer to per unit (pu) value and having low oscillations. The STFCL have very high and oscillatory rotor speed. The response of the DC chopper and crowbar is nearly same to the hybrid.

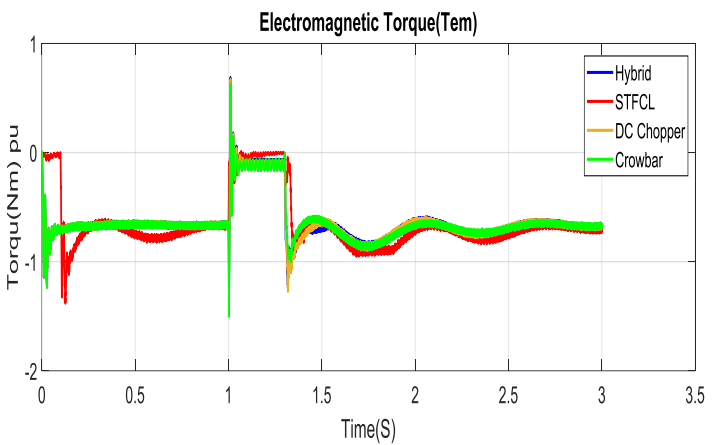

Fig 16: Electromagnetic Torque

Figure 16 shows the electromagnetic toque response during symmetrical (LLL-G) grid fault for the different strategies of grid interfaced DFIG. From the figure it is clear that the response of the STFCL is oscillatory and after fault it takes large time to stabilize. The response of hybrid is smoother and stabilize very soon after fault. DC chopper and crowbar have nearly same response as hybrid. 


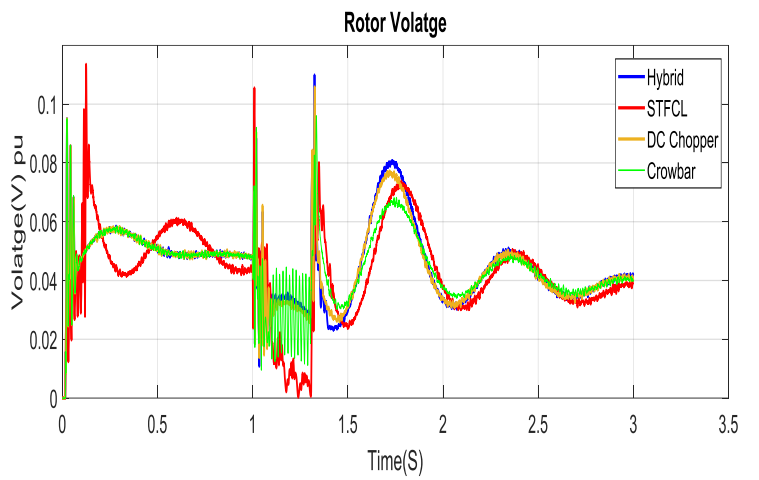

Fig 17: Rotor Voltage

Figure 17 shows the rotor voltage performance of different strategies for the grid interfaced DFIG during symmetrical (LLL-G) fault. STFCL has very high oscillations and peaks. The hybrid has lowest oscillation and smoother response of all strategies. The dc chopper and crowbar have response between the STFCL and hybrid.

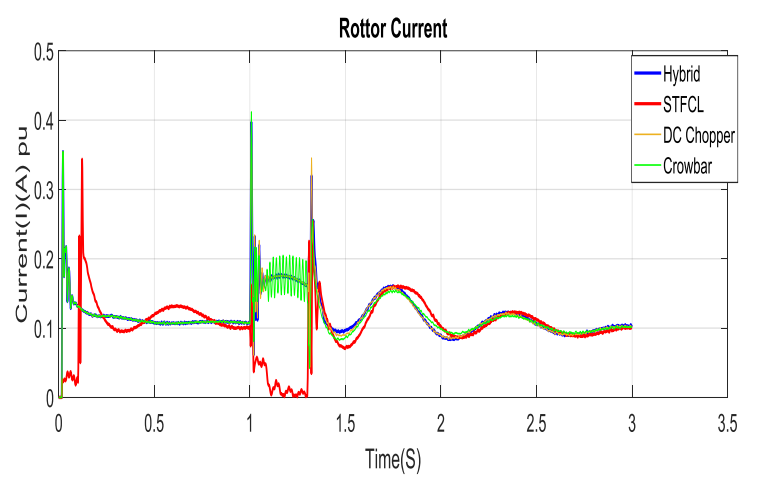

Fig 18: Rotor current

Figure 18 shows the rotor current response of different strategies for the grid interfaced DFIG during symmetrical (LLL-G) fault. The STFCL, DC chopper and Crowbar have very high oscillations and peaks but the Hybrid strategy has smooth and low oscillation and its current value is nearer to per unit (pu) value.

\section{CONCLUSION}

The LVRT strategies implemented on test bed model are (STFCL), DC chopper, Rotor Crowbar and Hybrid strategy with using RSC control, GSC control and pitch control mechanisms. The hybrid strategy provides excellent solution to the LVRT of DFIG based WT by controlling the active, reactive power and voltage of DC link. The results for the voltage of Grid and current, voltage of rotor and current, DC link voltage, active and reactive power, electromagnetic torque and rotor speed of hybrid strategy during symmetrical (three line to ground) (LLL-G) fault is best and well suited to the LVRT requirements as compared of STFCL, DC chopper and crowbar.

\section{REFERENCES}

[1] REN21. (2019). Renewables Global Status Report REN21. [Online] Available at: http://www.ren21.net/status-ofrenewables/global-status-report

[2] W. Qiao and R. G. Harley, "Grid Connection Requirements and Solutions for DFIG Wind Turbines," 2008 IEEE Energy 2030 Conference, 2008

[3] FERC - Interconnection of Wind Energy, 18 CFR Part 35, Docket No. RM05-4-001; Order No. 661-A December 12, 2005.

[4] B. B. Ambati, P. Kanjiya, and V. Khadkikar, "A Low Component Count Series Voltage Compensation Scheme for DFIG WTs to Enhance Fault Ride-Through Capability," IEEE Transactions on Energy Conversion, vol. 30, no. 1, pp. 208-217, 2015

[5] D. A and S. A "Comparison of fault ride-through strategies for wind turbines with DFIM generators". IEEE European conference on power electronics and applications, New York ,2005, Dresden, pp. 1-8.:

[6] J. Morren and S.W.H. de Haan, "Ridet hrough of wind turbines with doubly-fed induction generator during a voltage dip," IEEE Trans.Energy Convers., vol. 20, no. 2, pp. 435 - 441, June 2005.

[7] J. Lopez, P. Sanchis, X. Roboam, and L. Marroyo, "Dynamic behaviour of the doubly fed induction generator during three-phase voltage dips,' IEEE Trans. Energy Convers., vol. 22, no. 3, pp. 709 - 717, Sept. 2007.

[8] X. Kong, Z. Zhang, X. Yin and M. Wen, "Study of fault current characteristics of the DFIG considering dynamic response of the RSC," IEEE Trans. Energy Convers., vol. 29, no. 2, pp. 278-287, June. 2014

[9] W. Chen, F. Blaabjerg, N. Zhu, M. Chen and D. Xu, "Doubly fed induction generator wind turbine system subject to symmetrical recurring grid faults", IEEE Trans. Power Electron., early access, 2015.

[10] S. Seman, J. Niiranen, S. Kanerva, A. Arkkio, and J. Saitz, "Performance study of a doubly fed wind-power induction generator under network disturbances," IEEE Trans. Energy Convers., vol. 21, no. 4, pp. 883 - 890, December 2006.

[11] I. Erlich, H. Wrede, and C. Feltes, "Dynamic behavior of DFIG-based wind turbines during grid faults," in Proc. 38th IEEE Power Electronics Specialists Conference, Orlando, FL, USA, June 17-21, 2007, pp. 11951200 .

[12] A. Hansen, G. Michalke, P. Sørensen, F. Iov, and T. Lund, "Coordinated voltage control of DFIG wind turbines in uninterrupted operation during grid faults," Wind \& Solar Energy Journal, vol. 10, no. 1, Aug. 2006.

[13] P. Kumar and A. K. Singh." Grid Codes goals and challenges" Electrical Engineering Department, Motilal Nehru National Institute of Technology Allahabad, Uttar Pradesh 211004, India e-mail: pradeepkumar@ieee.orgA. K. Singh e-mail: asheesh@mnnit.ac.in

[14] K. E. Okedu, S. M. Muyeen, R. Takahashi, and J. Tamura, "Application of SDBR with DFIG to augment wind farm fault ride through," 2011 International Conference on Electrical Machines and Systems, 2011.

[15] R. Sarrias, L. M. Fernández, C. A. García, and F. Jurado, "Coordinate operation of power sources in a doubly-fed induction generator wind turbine/battery hybrid power system," Journal of Power Sources, vol. 205, pp. 354-366, 2012.

[16] F. Lima, A. Luna, P. Rodriguez, E. Watanabe, and F. Blaabjerg, "Rotor Voltage Dynamics in the Doubly Fed Induction Generator During Grid Faults," IEEE Transactions on Power Electronics, vol. 25, no. 1, pp. 118-130, 2010.

[17] S. Xiao, G. Yang, H. Zhou, and H. Geng, "Analysis of the control limit for rotor-side converter of doubly fed induction generator-based wind energy conversion system under various voltage dips," IET Renewable Power Generation, vol. 7, no. 1, pp. 71-81, 2013.

[18] W. Guo, L. Xiao, S. Dai, Y. Li, X. Xu, W. Zhou, and L. Li, "LVRT Capability Enhancement of DFIG With Switch-Type Fault Current Limiter," IEEE Transactions on Industrial Electronics, vol. 62, no. 1, pp. 332-342, 2015.

[19] K. Young, V. Utkin, and U. Ozguner, "A control engineers guide to sliding mode control," Proceedings. 1996 IEEE International Workshop on Variable Structure Systems. - VSS96 -.

[20] Mohan, Ned. Advanced electric drives: analysis, control, and modeling using MATLAB/Simulink. John wiley \& sons, 2014 
[21] Niiranen, Jouko. "Voltage dip ride through of a doubly-fed generator equipped with an active crowbar." In Nordic wind power conference, vol. 1. Chalmers University of Technology Sweden, 2004.

[22] J. K. Huusom, N. K. Poulsen, S. B. Jørgensen, and J. B. Jørgensen, "ARX-Model based Model Predictive Control with Offset-Free Tracking," Computer Aided Chemical Engineering 20th European Symposium on Computer Aided Process Engineering, pp. 601-606, 2010 .

[23] J. K. Huusom, N. K. Poulsen, S. B. Jørgensen, and J. B. Jørgensen, "Tuning SISO offset-free Model Predictive Control based on ARX models," Journal of Process Control, vol. 22, no. 10, pp. 1997-2007, 2012.

[24] R. Chudamani, C. Ramalingam, and K. Vasudevan, "Non-linear leastsquares-based harmonic estimation algorithm for a shunt active power filter,” IET Power Electronics, vol. 2, no. 2, pp. 134-146, 2009.

[25] S. Hu, X. Lin, Y. Kang, and X. Zou, "An Improved Low-Voltage RideThrough Control Strategy of Doubly Fed Induction Generator During Grid Faults," IEEE Transactions on Power Electronics, vol. 26, no. 12, pp. 3653-3665, 2011

Muhammad Naveed belongs to the Khyber Pakhtunkhwa province (KPK) Pakistan. He has got his bachelor degree in electrical power engineering from COMSATS University of science and Technology Islamabad (Abbottabad Campus) in 2015 and MSc Degree in electrical Power engineering from University of engineering and technology Peshawar Pakistan in 2019. His research area is Low voltage Ride through (LVRT) control of grid interfaced wind turbine (wind power generation in large grid system). 